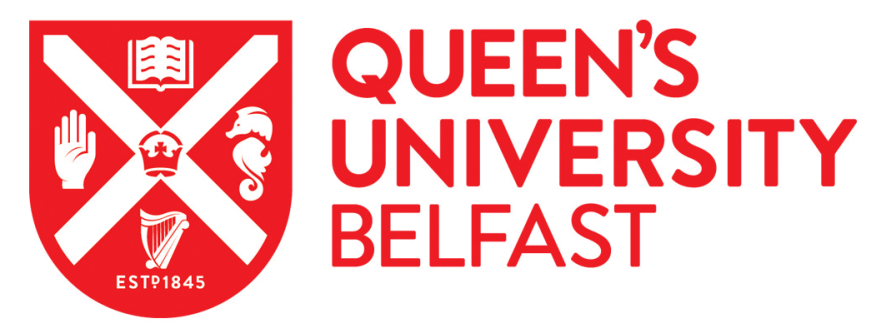

\title{
Cardiac or respiratory cause of hypoxia in a newborn
}

McKenna, M., Batchelor, G., O'Connor, B., McGowan, M., \& Conn, R. L. (2021). Cardiac or respiratory cause of hypoxia in a newborn. Archives of Disease in Childhood: Education and Practice Edition. https://doi.org/10.1136/archdischild-2020-321202

Published in:

Archives of Disease in Childhood: Education and Practice Edition

\section{Document Version:}

Peer reviewed version

Queen's University Belfast - Research Portal:

Link to publication record in Queen's University Belfast Research Portal

\section{Publisher rights}

Copyright 2021 the authors.

This is an open access Creative Commons Attribution-NonCommercial License (https://creativecommons.org/licenses/by-nc/4.0/), which permits use, distribution and reproduction for non-commercial purposes, provided the author and source are cited

\section{General rights}

Copyright for the publications made accessible via the Queen's University Belfast Research Portal is retained by the author(s) and / or other copyright owners and it is a condition of accessing these publications that users recognise and abide by the legal requirements associated with these rights.

Take down policy

The Research Portal is Queen's institutional repository that provides access to Queen's research output. Every effort has been made to ensure that content in the Research Portal does not infringe any person's rights, or applicable UK laws. If you discover content in the Research Portal that you believe breaches copyright or violates any law, please contact openaccess@qub.ac.uk. 
Cardiac or respiratory cause of hypoxia in a newborn?

McKenna M, ${ }^{1}$ Batchelor $\mathrm{G},{ }^{1}$ O’Connor B, ${ }^{1}$ McGowan $\mathrm{M},{ }^{1}$ Conn $\mathrm{RL}^{2^{*}}$

${ }^{1}$ Neonatal Intensive Care Unit, Ulster Hospital, Dundonald, United Kingdom, BT16 1RH

${ }^{2}$ Centre for Medical Education, Queen's University Belfast, Belfast, United Kingdom, BT9 $7 \mathrm{BL}$

${ }^{*}$ Corresponding author

Dr Richard Conn,

Centre for Medical Education,

Whitla Medical Building,

97 Lisburn Road,

Belfast

BT9 7BL

E-mail: r.conn@qub.ac.uk

ORCID iD: https://orcid.org/0000-0002-2564-254X

Word count: 637

Key words: Neonatal resuscitation, imaging, congenital cardiac disease 


\section{Cardiac or respiratory cause of hypoxia in a newborn?}

A term baby boy was delivered overnight by emergency caesarean section for pathological cardiotocography. An uncle died in childhood due to 'a problem with the aorta'.

After initial cry he required resuscitation including chest compressions. He was stabilised on nCPAP but remained poorly saturated with a notable pre- and post-ductal gradient.

Cardiovascular examination was normal. A chest x-ray was taken at two hours of life (Figure 1).

\section{QUESTION 1}

'Egg on a string sign' suggests which congenital cardiac condition?
A. Coarctation of the aorta
B. Ebstein anomaly
C. Tetralogy of Fallot
D. Total anomalous pulmonary venous return
E. Transposition of the great arteries

\section{QUESTION 2}

What pathological finding is seen on this $\mathrm{x}$-ray?

\section{QUESTION 3}

What emergency treatment should be considered?

\section{QUESTION 4}

Which investigation would be most helpful in guiding ongoing management? 


\section{ANSWERS TO THE QUESTIONS}

\section{Question 1: The correct answer is E}

The 'egg on a string' sign (or 'egg on its side'), brought to mind by the globular cardiac shadow on this neonatal chest $x$-ray, is suggestive of transposition of the great arteries (TGA).

TGA is a congenital cardiac condition in which the aorta arises from the morphologic right ventricle and the pulmonary artery from the morphologic left ventricle. ${ }^{1}$ Systemic and pulmonary circulations are parallel and a connection must exist - a septal defect or a patent ductus arteriosus - to sustain life.

If not antenatally diagnosed (as many as $50 \%$ of cases $^{2}$ ), TGA presents with severe cyanosis followed by progressive metabolic acidosis due to poor oxygenation. Diagnosis is challenging as clinical examination is generally unremarkable, except for a single, loud second heart sound, and there may be no murmur unless associated anomalies are present. The characteristic radiographic appearance represents a narrowed superior mediastinum, an enlarged left atrium and an abnormally convex right atrium due to increased pulmonary blood flow. ${ }^{3}$ Together, these features give rise to a globular, egg-like heart shadow.

In this case, the presentation, $x$-ray appearance and family history, in conjunction with the well-recognised difficulty in clinically diagnosing congenital heart disease, led to concern about a potential cardiac cause of hypoxaemia.

\section{Question 2: Right-sided pneumothorax}

Besides the concerning cardiac appearance, this x-ray shows a clear pathological finding of right-sided pneumothorax. This gives rise to the question of whether congenital heart disease could be present in addition to pneumothorax, or whether the abnormal heart shadow may actually be a 'red herring' that does not indicate a primary cardiac problem.

\section{Question 3: Needle thoracocentesis}


Faced with diagnostic uncertainty, treatment for life-threatening conditions should be prioritised. In a hypoxic, clinically unstable neonate with pneumothorax, urgent needle thoracocentesis is indicated, followed by chest drain insertion if the air leak persists. In this case, however, the infant improved with nCPAP, and thoracocentesis was avoided.

Although duct-dependent cardiac disease was considered, (and prostaglandin prepared); prompt bedside echocardiography by the neonatologist was performed to guide care, and manage the baby safely without invasive procedures.

\section{Question 4: Echocardiography}

Echocardiography is the mainstay of investigation to diagnose or rule out congenital heart disease.

Other clinical findings hint at the diagnosis including 1) the differential in pre- and post-ductal saturations and 2) close examination of the radiograph reveals elevation of the thymus and outlining of the cardiac silhouette, suggestive of a small pneumomediastinum.

In this case, echocardiography showed normal ventriculoarterial connections, excluding the diagnosis of TGA. Instead, pulmonary hypertension associated with the pneumothorax was causing right atrial dilatation. The aortic knuckle was pulled to the right and the vascular pedicle narrowed, findings which conspired to mimic the egg on a string sign. Air leak rather than TGA explained the baby's clinical status.

This case emphasises the difficulty of clinically differentiating between cardiac and respiratory causes of hypoxaemia in an unwell newborn. In particular, the weakness of radiological cardiac contour at identifying congenital cardiac disease is well recognised ${ }^{4}$ and highlights the value of clinicians outside cardiac centres being trained in echocardiography. Careful radiographic interpretation may also be also useful - e.g. in this image, in identifying the pneumomediastinum (which offered an alternative explanation for the narrow vascular pedicle) and helping to discern the configuration of the great vessels (Figure 2). Nevertheless, the principle remains that, in the face of ongoing clinical instability and diagnostic doubt, life-saving treatment should be prioritised; in this case, by aspiration of the pneumothorax (by needle or drain, under mechanical ventilation), prior to repeat x-ray.

\section{PATIENT OUTCOME:}


The baby improved after optimising respiratory support and was later discharged to the maternity ward, with cardiology follow-up as a safety net.

\section{References}

1. Warnes CA. Transposition of the great arteries. Circulation 2006;114(24):2699-2709. doi:10.1161/CIRCULATIONAHA.105.592352

2. Escobar-Diaz MC, Freud LR, Bueno A, et al. Prenatal Diagnosis of Transposition of the Great Arteries over a 20-Year Period: Improved but Imperfect. Ultrasound Obst Gynecol 2015;45(6):678-682. doi:10.1002/uog.14751.Prenatal

3. Ferguson EC, Krishnamurthy R, Oldham SAA. Classic image signs of congenital cardiovascular abnormalities. RadioGraphics 2007; 27(5):1324-1325. Available at: https://pubs.rsna.org/doi/pdf/10.1148/rg.275065148 (Accessed 9th November 2020).

4. Laya BF, Goske MJ, Morrison S, et al. The accuracy of chest radiographs in the detection of congenital heart disease and in the diagnosis of specific congenital cardiac lesions. Pediatr Radiol 2006;36(7):677-681. doi:10.1007/s00247-006-0133-2

Acknowledgements: None

Competing interests: None

Funding: None

Patient consent: Obtained 
Figure 1

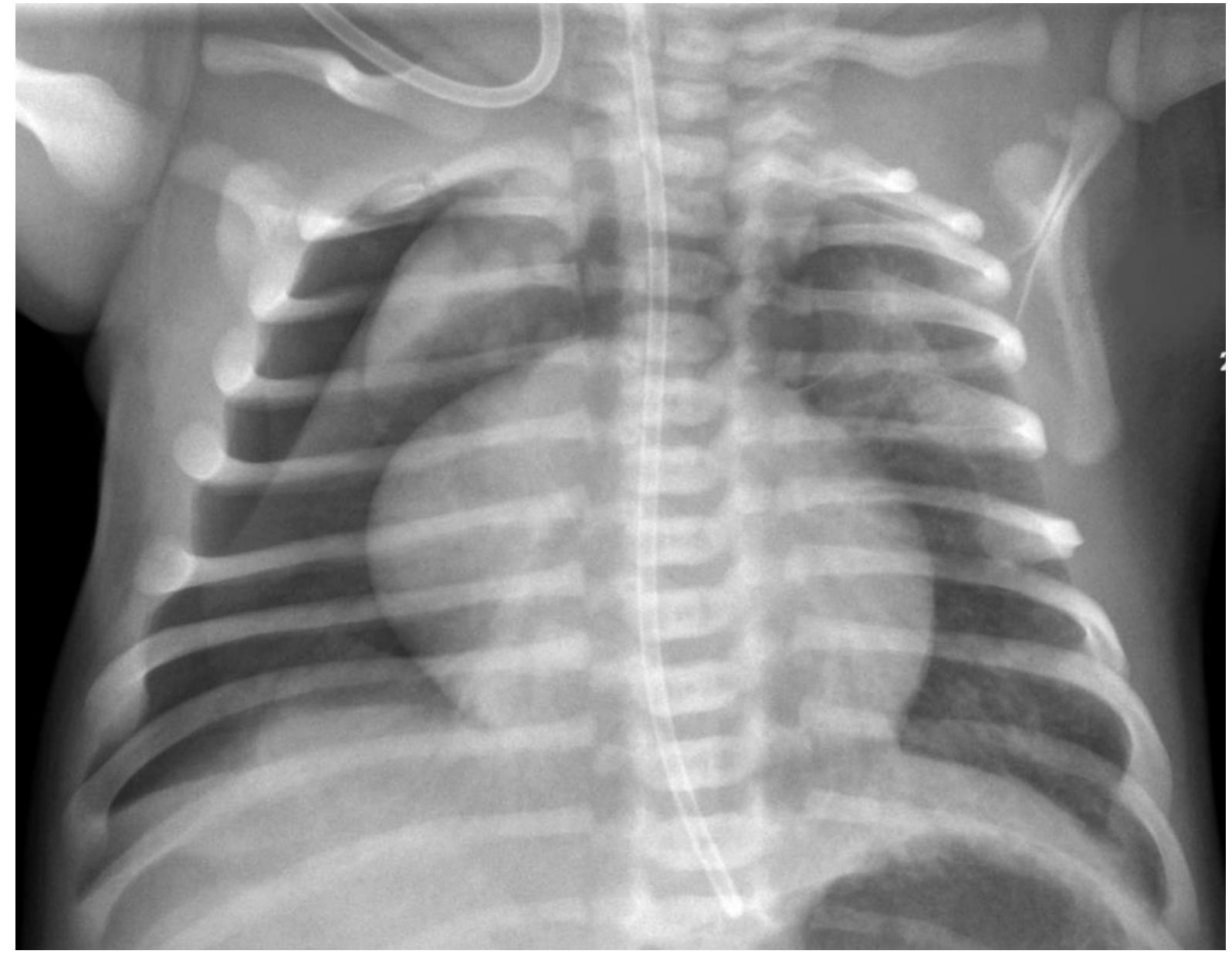


Figure 2

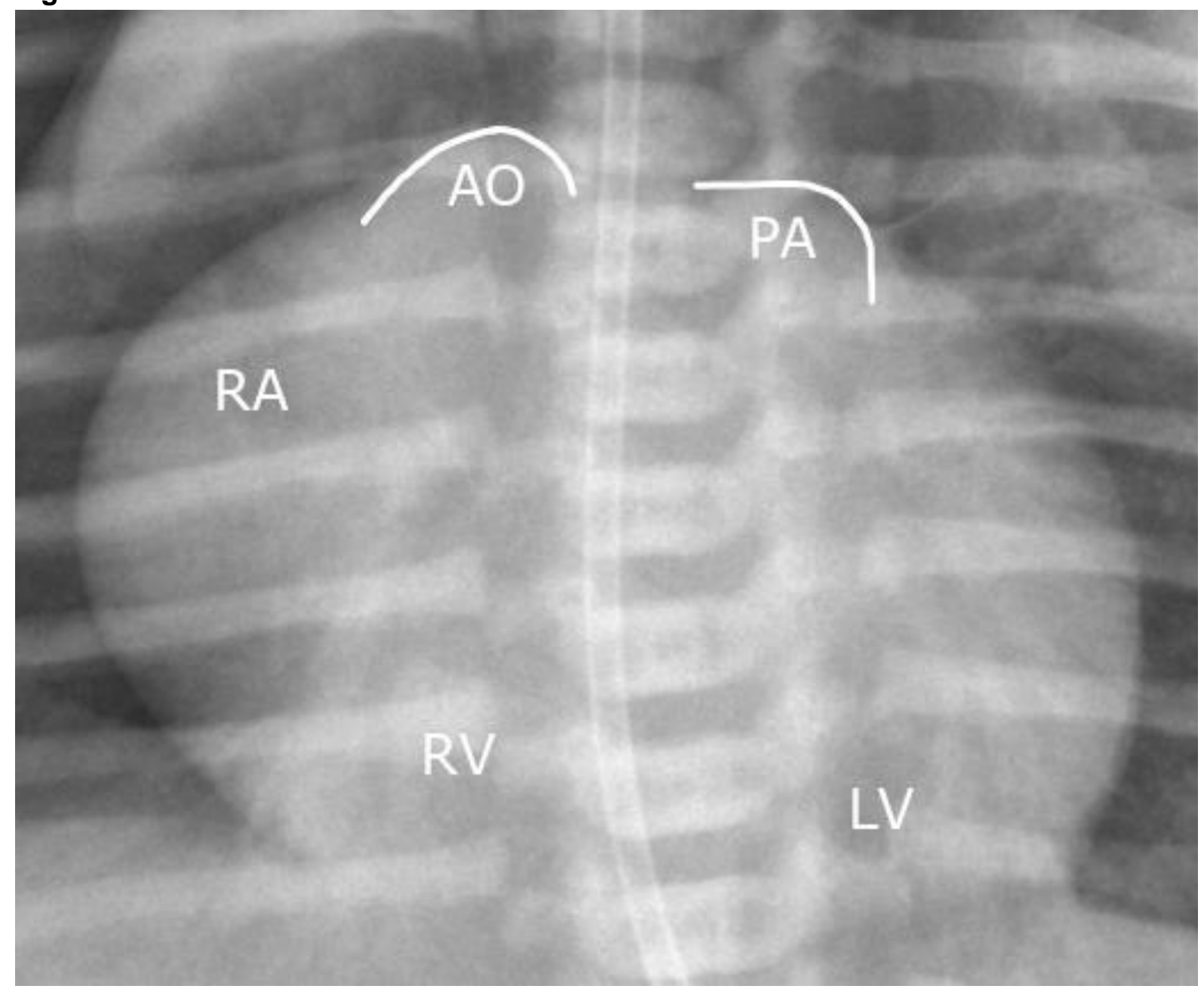

